\title{
Erratum to: Kai-Florian Richter and Stephan Winter: \\ Landmarks-GIScience for Intelligent Services
}

Springer International, Cham, Switzerland, 2014, xv + 223 pp., ISBN 978-3-319-057316, ISBN 978-3-319-05732-3 (eBook)

Toru Ishikawa ${ }^{1}$

Published online: 8 February 2017

(C) Springer-Verlag Berlin Heidelberg 2017

\section{Erratum to: Künstl Intell}

\section{DOI 10.1007/s13218-016-0469-1}

Some of the bibliographic data relating to the reviewed book were missing. The complete information is given above. The original article has been corrected.

The online version of the original article can be found under doi:10.1007/s13218-016-0469-1.

Toru Ishikawa

ishikawa@csis.u-tokyo.ac.jp

1 Graduate School of Interdisciplinary Information

Studies, University of Tokyo, 7-3-1 Hongo, Bunkyo-ku,

Tokyo 113-0033, Japan 